\title{
THE DATA RELIABILITY OF VOLUNTEERED GEOGRAPHIC INFORMATION WITH USING TRAFFIC ACCIDENT DATA
}

\author{
H. K. Sevinç ${ }^{1}$, I. R. Karaş ${ }^{2}$ \\ ${ }^{1}$ Ayancik Vocational School, Sinop University 57400 Ayancik Sinop, Turkey - hacerkubra@ gmail.com \\ ${ }^{2}$ Faculty of Engineering,Computer Engineering Department, Karabuk University 78050 Karabuk, Turkey - irkaras@gmail.com
}

KEY WORDS: Volunteered Geographic Information, Citizen science, Traffic Accidents, Participant

\begin{abstract}
:
The development of mobile technologies is important in the lives of humans. Mobile devices constitute a great part of the daily lives of people. It has come to such a point that when people first wake up, they check their smart phones for the first thing. Users may share their positions with the GNSS sensors in mobile devices or they can add information about their positions in mobile applications. Users contribute to Geographical Information System with this sharing. These users consist of native (citizens) living in that geographical position not of the CBS specialists. Creating, collecting, sharing and disseminating the geographical data provided by voluntary individuals constitute the Volunteered Geographic Information System. The data in the Volunteered Geographic Information System are received from amateur users.
\end{abstract}

"How reliable will the data received from amateur users instead of specialists of the field be in scientific terms?" In this study, the reliability between the data received from the voluntary users through Volunteered Geographic Information System and real data is investigated. The real data consist of the traffic accident coordinates. The data that will be received from users will be received through the speed values in the relevant coordinates and the marking of the users for possible accident points on the map.

\section{INTRODUCTION}

In recent years, contribution of people to online data has become a necessity. The undeniable power of social media is reflected in geographical information systems. People share the places they live, the destinations they visit, and the places where they spend their daily lives in social media. Users participate and contribute voluntarily to geography-based information systems in social media such as OpenStreetMap, Flicker, Foursquare, Waze, Twitter, etc. In this study, the use and reliability of Volunteered Geographic Information System in Turkey will be investigated.

Volunteered Geographic Information (VGI) defines the creation of spatial data by a great number of citizens who mostly do not have any official education on this field (Goodchild, 2007). Social Media sites allow users to share their own contents in digital communities in an online manner. VGI systems are the geography-based social media sites, and the thing that constitutes the geographical data is the users of these sites.

Fast and Rinner (2014) conducted a study and defined the Volunteered Geographic Information system as Project, Participant and Technical Infrastructure. They claimed that these components were at a complex design (Figure 1). Here, Project refers to a problem, a political crisis or the natural disasters that are triggered. Participant sends the signals through smart phones or mobile devices by using GPS and similar technologies. Users contribute to the geographical information by entering Geoweb Medium and by adding the signals to the map in a voluntary manner. Technical Infrastructure supports the VGI formation. Each system has a unique hardware and software component. VGI systems include hardware components, server and client computers, GPS units or position-based devices like smart phones. Software component includes the open source platforms like ArcGIS Online or Ushahidi and some closed source platforms. In addition, technical infrastructure has two sides; user interface or client-side architecture and developer or server-side architecture (Fast \& Rinner, 2014)

Participant sources are ensured through Crowdsourcing, which was first mentioned by Howe in 2006. Crowdsourcing means providing the data from the people who have the relevant data in an area with Internet connection instead of making one single employee do this. In this respect, the position of the users is not important. Wikipedia: The online encyclopaedia to which multiple users may add data; iStockPhoto: The photograph sharing platform to which users may add photographs; OpenStreetMap: The community to which users may add map data are examples for this.

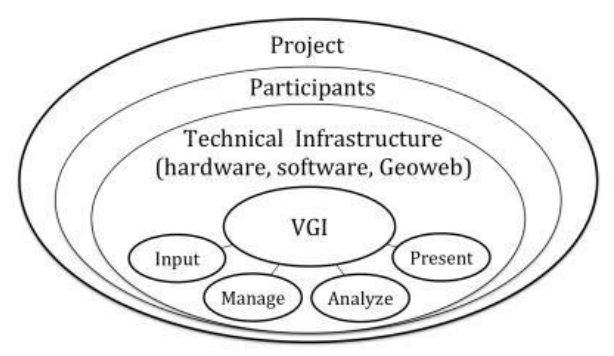

Figure 1. VGI System Components

In Figure 2, there is a map illuminated by using the GNSS data shared by users who employ Waze Application. This map shows the road network of the streets and alleys of New York at 8.50 through GNSS data (Waze, 2014). 


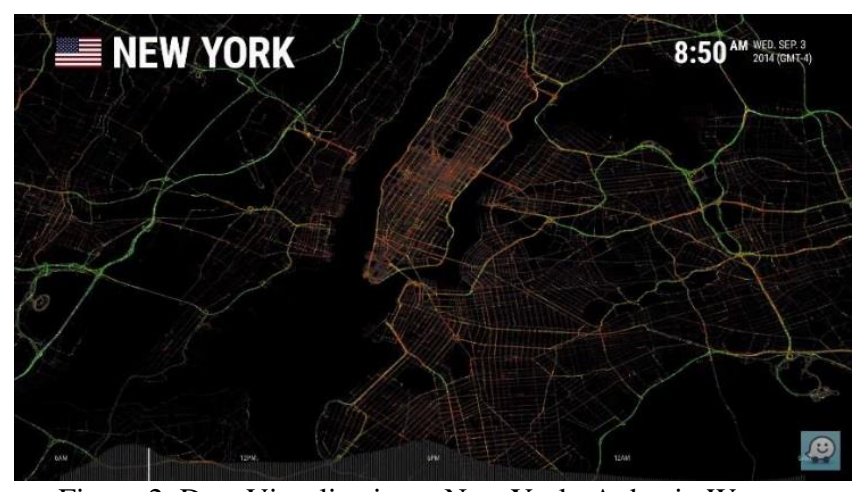

Figure 2. Data Visualization - New York: A day in Waze

According to 2016 traffic accident data, drivers' mistakes are the first factor among the reasons that cause traffic accidents (with death-injuries) (Figure 3). The most frequent factor that cause accidents among the drivers' mistakes is the "Not adjusting the speed of the vehicle according to the road, air and the conditions required by traffic" (Traffic Education and Research Department, 2017).

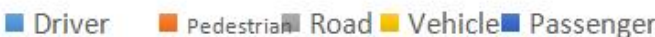

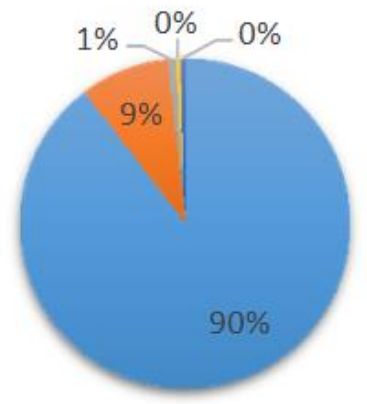

Figure 3. The Elements that Cause Traffic Accidents

In this study, the data of traffic accidents in Sinop between the years 2011-2015 were used as the sample dataset. The data were received from General Directorate of Security Affairs, Traffic Research Department

In this study, traffic accidents will constitute the Project Component, drivers will constitute the Participant Component, and the android-based system will constitute the Technical Infrastructure component. (Figure 4)

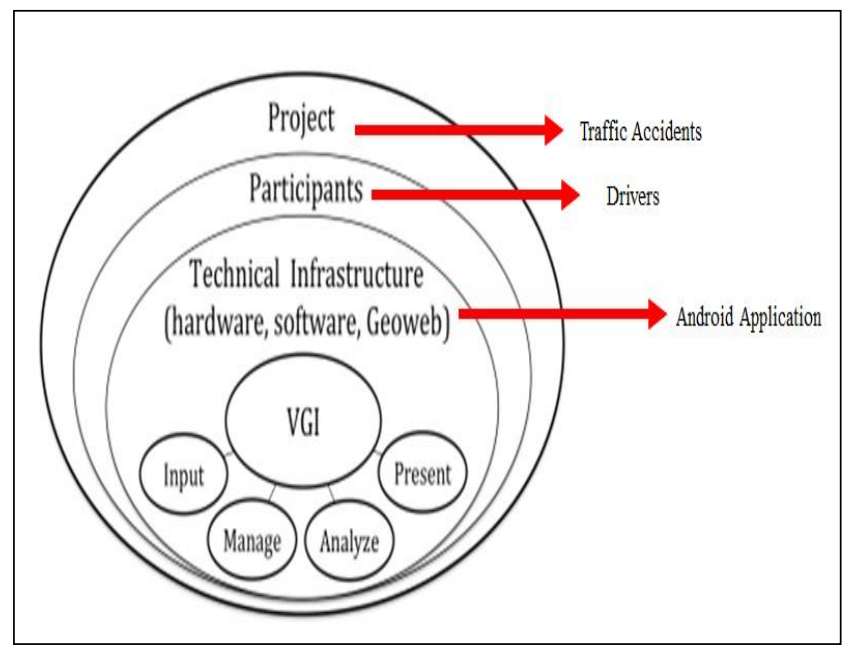

Figure 4. System Components

\section{MATERIALS AND METHODS}

The purpose of the planned system is to receive geographical data from users for Volunteered Geographic Information by developing a mobile-based application (it is planned that it will be an android-based one). The incoming data will be recorded in the database server. It is aimed with the recorded data that the relation between the points where traffic accidents happen frequently will be determined. (Figure 5)

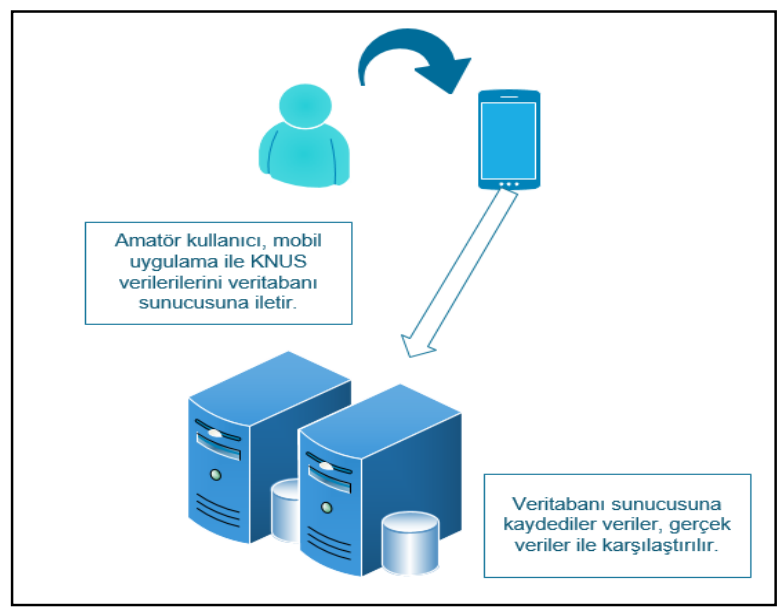

Figure 5. Block diagram of operation

When the GNSS is active on the mobile devices of the users, the speed values will be recorded during the vehicle use durations. These data will be compared with the data of the traffic accidents within a time period between 2011-2015 received from General Directorate of Security Affairs, Traffic Research Department. In addition, users are expected to mark the potential accident points on the roads. In this way, comparisons will be made between the data received from the users and the real data, and reliability analysis will be performed. In our study, the Accident Number Method, which is one of the Accident Black Point Analysis Methods, will be used. The Accident Number Method is also named as the "Mapping Method" or the "Accident Frequency Method". In this method, the number of the accidents that happen within a certain road section is determined (Koldemir, 2009). In this study, the important thing is the coordinate where accidents happen. The proximity of the coordinates and the visualization made with GIS software are shown in Figure 6.

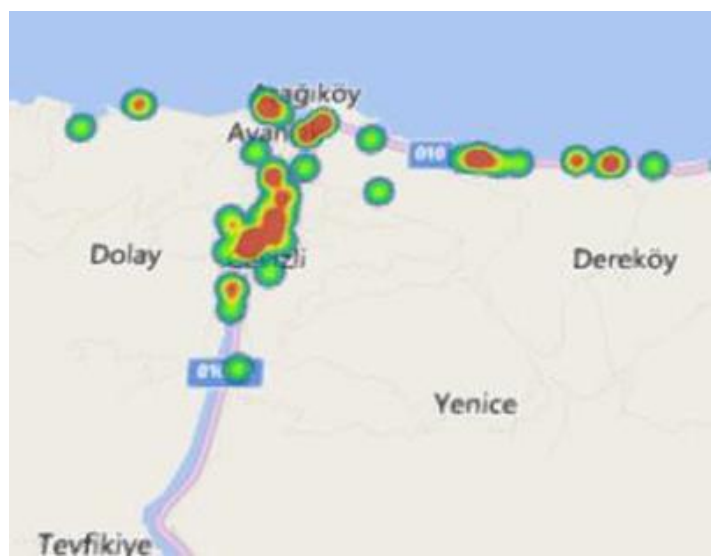

Figure 6. Sinop, Ayancık Trafic accidents intensity (real data) 
In this study, it is planned that the following methods are used: The program will be android-based, because the target audience is the users. According to the data reported by Gartner (2015), the rate of using mobile phones all over the world (including tablet and PCs) are shown in Figure 7.

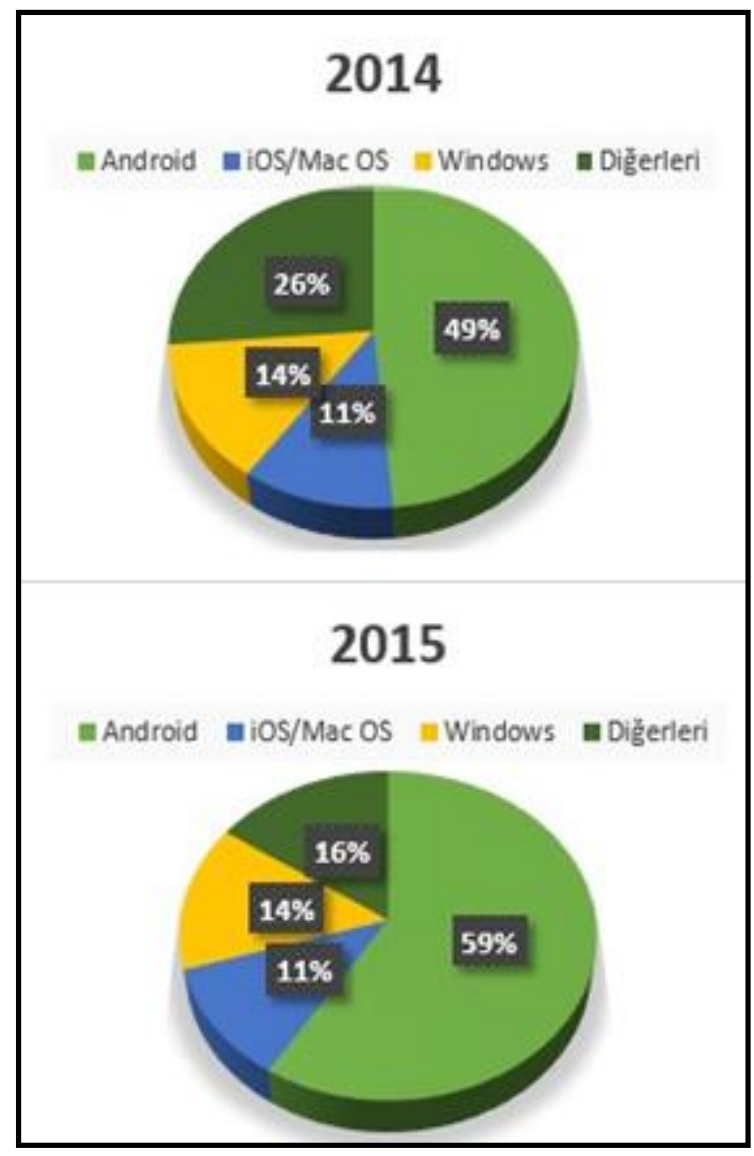

Figure 7. Android versions usage rates

- The KitKat 4.4 version is the most frequently used one among android versions with $35.5 \%$ according to February 2016 data. Lollipop version 5.0 and 5.1 versions follow KitKat with $34.1 \%$ (Andorid, 2016). It is planned that one of these two versions will be used in program development period in the study.

- After the application is developed, it will be uploaded to Google Play Store for users to download and use.

- The position data of users will be compared with the online data, and reliability assessments will be made.

- The relation between the traffic accident data received from Traffic Education and Research Department and the geographical information that will be received from users will be assessed.

\section{CONCLUSIONS}

The system will compare the real data and the users' data, and provide opinion on the reliability of the voluntary geographical data. If the expected results are achieved, in further studies, when the driver approaches the accident point, the application in the smart phone will provide a warning signal and the driver will be asked to be careful. Yandex Navigation System gives an audio warning signal when the driver exceeds the speed limit defined by users. This application can be improved to give an audio signal when the driver approaches accident points. In this way, the drivers' mistakes can be reduced to prevent traffic accidents.
Existing navigation systems guide the driver to alternative routes in case of a traffic jam by receiving the speed of the driver. Even for navigation systems, the most important thing is not the shortest route but it is the shortest time. In addition, Volunteered Geographic Information also reduces user costs. Instead of the price that will be paid to the specialist employee, data will be received from amateurs who have information on the relevant position.

Volunteered Geographic Information will appear before us with different applications in the future. People prefer the applications in which they are included and with which they can share their information. In further studies, the data received from users will be processed in an accurate manner, and the system will guide other users. More and more sensors are added to mobile devices with each passing day. This variety of sensors will enable us to perform many things that seem difficult now in a simpler way with Crowdsourcing.

\section{REFERENCES}

Goodchild, M., 2007. Citizen as sensors: The world of volunteered geography. GeoJournal, 211-221.

Fast, V., \& Rinner, C., 2014. A Systems Perspective on Volunteered Geographic Information. ISPRS Int. J. GeoInf(Volume 3, Issue 4), 1278-1292. doi:10.3390/ijgi3041278

J. Howe, 2006. The Rise of Crowdsourcing, [online] Available: https://www.wired.com/2006/06/crowds/

Trafik Eğitim ve Araştırma Dairesi,. 2017. Ístatistikler. Emniyet Müdürlüğü Trafik Hizmetleri Başkanlığı [online] Available: http://www.trafik.gov.tr/SiteAssets/istatistik/2016d.pdf

Gartner. 2015. Gartner Says Tablet Sales Continue to Be Slow in $2015 . \quad$ [online] Avaible: http://www.gartner.com/newsroom/id/2954317

Koldemir, B., 2009. Seyir Güvenliği Açısından Istanbul Boğazında Riskli Bölgelerin Belirlenmesi; Kaza Kara Noktalarınin Güncellenmesi. Dokuz Eylül Üniversitesi Denizcilik Dergisi, 17-26. 